\title{
O DIREITO DE ESTUDAR O INDÍGENA: SEDUÇÃO, ESTRANHAMENTOS E DIFERENÇA EM SALAS DE AULA
}

\begin{abstract}
RESUMO: Este artigo trata de forma arrazoada do campo de atuaçáo da Lei no $11.645 / 08$, a lei de obrigatoriedade do ensino indígena, aplicada no Estado do Rio de Janeiro. Irei analisar escolas da rede pública e um instituto de aplicação que contempla projetos acerca da lei e a produção de materiais didáticos sobre povos indígenas. $\mathrm{O}$ artigo não trata de um método comparativo entre as instituiçóes nem de uma amostragem de métodos didáticos para a aplicação da lei que "funcionam". Entender o conflito, a sedução e os estranhamentos quando mundos indígenas são apresentados a crianças é um dos pontos centrais deste artigo.
\end{abstract}

Palavras-chave: Lei no 11.645/08. Estranhamento. Diferença.

\section{The right to study the indigenous: seduction, stressing and difference in classrooms}

ABSTRACT: This paper shows in an appropriate way the field of action of Law 11.645/08, the law of obligation of indigenous education, applied in the State of Rio de Janeiro. I will analyze public schools and an application institute that contemplates projects on the law and the $p$ roduction of didactic material about indigenous peoples. The paper is not a comparative method

${ }^{1}$ Universidade do Estado do Rio de Janeiro - Rio de Janeiro (RJ), Brasil.

E-mail: daniellebastoslopes@hotmail.com

DOI: $10.1590 / C C 0101-32622019217866$ 
between institutions, nor a sampling of didactic methods for law enforcement that "working". Seeking to understanding the conflict, seduction and estrangement when indigenous worlds are presented to children is one of the central points of this paper.

Keywords: Law 11.645/08. Stressing. Difference.

Esse olhar do dito "animal" me dá a ver o limite abissal do humano: o inumano, a-humano, os fins dos homens, ou seja, a passagem das fronteiras (DERRIDA, 2011, p. 31).

\section{INTRODUÇÃO}

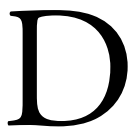

e acordo com Bruno Latour (2013, p. 9), "nós mesmos somos híbridos, instalados precariamente no interior de instituiçóes científicas". Partindo desse princípio analiso as relações de ocidentalização e ensino, tradicionalmente descritas como ensino sobre culturas indígenas na educação básica. Este artigo se debruça sobre casos particulares e localizados; o estudo de um instituto que experiencia um projeto sobre culturas ameríndias para crianças trazendo, paralelamente, relatos de professores da rede pública do Rio de Janeiro de modo amplo. Analisa-se, assim, a implementação da lei que aprovou a obrigatoriedade do ensino sobre culturas africanas e indígenas nos currículos.

$\mathrm{O}$ foco não recai em um estudo comparativo entre o instituto e os professores da rede pública. Antes que uma comparação entre universos específicos e variados (STRATHERN, 1999; 2014), analisam-se as escalas e a variação do ensino sobre indígenas. Os afastamentos, a sedução e as convergências são comuns quando "mundos ameríndios" são apresentados a crianças em idade escolar. Desse modo, ainda que em um ambiente acadêmico híbrido, como afirma Latour (2013), tentarei demonstrar como "nossas" formas de ensinar "o outro" baseiam-se em uma linguagem tipicamente humana, racional e desencantada (CHAKRABARTY, 1992; 2011; 2012). 


\section{O INSTITUTO E AS ESCOLAS DA REDE PÚBLICA DO RIO DE JANEIRO}

O Instituto Fernando Rodrigues da Silveira, conhecido como CAp-UERJ, é evidenciado como uma instituição de excelência no Estado carioca. O termo excelência abrange discussóes sobre escalas, parâmetros e, consequentemente, as evasóes e os espectros de repetência, cujos modelos de escolaridade e avaliação não mencionam (BARRIGA, 2015). Não avançarei na discussão neste artigo, contudo, quero ressaltar a quantidade considerável de pesquisadores e docentes que analisam os conceitos qualidade e avaliação total, destacadamente o caso do CAp-UERJ (ALMEIDA, 2016; OLIVEIRA, 2014).

No âmbito do Estado, a pesquisa foi produzida com professores das redes estaduais e municipais de ensino; as três escolas foram as mesmas pesquisadas em 2013 quando analisei a obrigatoriedade do ensino indígena ainda emergente (BASTOS LOPES, 2013). Escolhemos professores da rede pública devido a grande maioria dos profissionais cursar graduaçóes e especializaçóes em universidades igualmente gratuitas, segundo o Ministério da Educação e Cultura (MEC). Ou seja, a rigor, teríamos um público múltiplo, próximo às políticas e aos currículos nacionais. Os apontamentos servem, nesse sentido, para uma revisita aos dados encontrados em 2013, ainda que não tenhamos a intenção de "respostas últimas" para a temática intercultural indígena no ensino.

\section{CURRÍCULO E DIFERENÇA}

Nas reformas curriculares ibero-americanas os textos para "inclusão" indígena apresentam divergências, tanto quanto se conectam (CEPAL; UNESCO, 2018; DIAS, 2014). Os debates adquiriram centralidade a partir dos anos 1990-2000 com influência da Organização das Naçóes Unidas para a Educação, a Ciência e a Cultura (UNESCO) e dos países latino-americanos sendo incorporados, anos depois, às Diretrizes para a Educação das Relaçóes Étnico-Raciais no Brasil (CORTÉS; APODACA, 2016; ROCKWELL, 2015; YAPU, 2015). As diretrizes concebem a figura do indígena e do negro como 
"ensino sobre"; o que é potencialmente complexo, mas expressivo, como argumentarei a seguir.

De acordo com os teóricos desconstrucionistas, o currículo é subsumido pela diferença (MACEDO, 2013; 2017; MILLER, 2014). O pós-estruturalismo interroga correntes que defendem o centralismo em identidades humanistas e incontaminadas, assim como teorias que agenciam "o projeto de reconhecimento do sujeito em sua cultura, em sua sociedade, em comunidades racionais” (MACEDO, 2017, p. 545). As identidades são proeminentemente mais relacionais e híbridas do que críticas ou normativas.

Essas noçóes aparecem em artigos anteriores, entretanto, argumento que conceitos como identidade, currículo, cultura, que ressoam constantemente no que traduzem como prática pedagógica, no caso deste artigo, chamo de ocidentalização e "estranhamentos" quando analisamos culturas indígenas no ensino (BASTOS LOPES, 2013; 2017). Se movimentar a concepção de identidade como algo puramente étnico (GELLNER, 1995) aprisiona possibilidades e sistemas de vida na lógica da apropriaçáo, argumentarei que a negação da identidade indígena não nos coloca no lugar confortável, "consciente" (STRATHERN, 2014; VILAÇA, 2013) de entender a experiência do reconhecimento, ou mesmo sua representaçáo, como "um somatório de constantes" (VIVEIROS DE CASTRO, 2004) ou o que pode ser puramente evitado (MACEDO, 2017). Como afirmaria Latour (2013), sabemos que a humanidade não é uma coisa ou mercadoria, mas "as mercadorias também não são indistintamente mercadorias ou coisas".

Pensar a Lei $\mathrm{n}^{\mathrm{o}} 11.645$ em um contexto que tem extinguido debates sobre cultura, interculturalidade e, em certa medida, representaçóes evidencia como "o ensino sobre" abre espaço para novos sistemas de inteligibilidades, ainda que seja para negarmos um ensino indígena realista, abjeto e desencantado (CHAKRABARTY, 1992; 2011; 2012).

\section{"TER" DE ENSINAR PORQUE É OBRIGATÓRIO, "TER" DE ENSINAR PORQUE DESCONSTRÓI}

Passemos ao campo ${ }^{1}$ e aos usos da lei, entendendo currículo (MACEDO, 2017; MILLER, 2014), portanto, como um híbrido entre pensamento e contradiçóes, contradições e possibilidades assimétricas (SMITH, 2012; STRATHERN, 2014). 
Foram realizadas 50 entrevistas em um universo de 5 escolas. Meu trabalho não produziu entrevistas semiestruturadas, como ocorreu em 2013; optei, dessa vez, pela participação em projetos nas escolas, muitos com observação e no instituto CAp-UERJ, coordenei programas de ensino com culturas indígenas (BASTOS LOPES, 2013).

Nos últimos anos, uma fala recorrente entre as escolas marca a falta de autores ameríndios nos materiais didáticos. Existiria pouco ou nenhum espaço para "outra visão", segundo os professores (BASTOS LOPES, 2013; BANIWA, 2011). Nesse contexto, embora exista uma cultura pedagógica que atesta "métodos eficazes" e "materiais eficientes" (MILLER, 2014), as instituiçóes exploram objetos e materiais didáticos não objetificados, exercendo um desvio no sentido tradicional do uso dos livros.

É comum as escolas adotarem a filmografia, o grafismo, a arte plumária, entre outros acervos, sem estarem incluídos, necessariamente, no Plano Nacional do Livro Didático ${ }^{2}$. Todos os materiais, no entanto, são entendidos como pedagógicos, movimentando corpos e estranhamentos.

Os materiais didáticos nós que criamos, produzimos uma pesquisa própria. Os livros que recebemos são bons, mas tem pouca participação indígena. Queríamos algo das próprias comunidades. A questão é que acho complicado o ensino indígena ser uma obrigação, ninguém é obrigado a ensinar nada, ou mesmo aprender nada [sic]. Sabemos que funciona assim. Porém, não posso deixar de entender como esta Lei é importante para chamar atenção para as questôes indígenas e africanas. Olha que absurdo! [sic] É preciso que o Estado obrigue a ensinar sobre sociedades que fizeram parte da construção histórica do Brasil.

Eu ensino porque quero, porque desconstrói, não porque é obrigatório. Essa desconstrução que as culturas indígenas especialmente causam nos alunos ao ver outros sistemas, meios de comunicação e tecnologia é o que mais me estimula a pesquisar, são formas de linguagem e mundo muito diferentes (PROFESSORA DA REDE MUNICIPAL DE ENSINO. Entrevista concedida à autora em março de 2018). 
Um estudo produzido por autores ameríndios norte e sul-americanos (BANIWA, 2011; TAIAIAKE, 2009) demonstrou como os livros utilizam uma linguagem humanista ${ }^{3}$ e racional para ensinar conceitos não humanos e sagrados indígenas (BANIWA, 2011; BENITES, 2012; OLIVEIRA; BASTOS LOPES, 2016).

Como aponta Dispesh Chakrabarty (1992; 2011; 2012), na Índia, quando os elementos sobrenaturais participam das circulaçóes do Ocidente, contrastam-se os efeitos violentos e normativos que estruturam conhecimentos sagrados em uma linguagem desencantada. Chakrabarty (2012), Appadurai $(1986,2013)$ e Said (2007) interrogam o uso de categorias genéricas para referirem-se a conceitos indianos levados aos países europeus. Aqui, aproximo suas análises aos materiais que chegam às escolas, traduzidos em larga escala com uma linguagem realista e universalizante (BANIWA, 2011; OLIVEIRA; BASTOS LOPES, 2016).

A entrevista exalta os contextos assimétricos entre "o ensinar porque desconstrói” e, ao mesmo tempo, "o ensinar como obrigação". É interessante como o currículo étnico-racial ocupa temas interdisciplinares com projetos relevantes, mas concebidos como inteiramente Outro; o ensino que está fora do currículo e, a partir de políticas para o diferente, é "incluído" como ensino (MACEDO, 2013; 2017).

A política concebe, portanto, corpos, identidades e gêneros bem marcados e sintagmáticos. A visão exprime o olhar do observador, que pode observar sem ser visto e descrever a partir das naturezas do corpo não marcado; um grupo, uma família, objetos, por exemplo (STRATHERN, 1999; 2014). Embora a visão desencadeie semióticas e formas para entender contextos diferentes, o observador privilegiado em não "marcar o corpo" é possivelmente branco, ocidental e compreende mais de dois ou três idiomas distintos (HARAWAY, 1991; 1995; SMITH, 2012). Como afirmou D. Haraway (1995, p. 22), "todos os olhos, incluindo os orgânicos movem sistemas perceptivos ativos, construindo traduçóes e maneiras específicas de ver, isto é, modos de vida". "Com o sangue de quem são feitos meus olhos?” (HARAWAY, 1995, p. 25), sugere uma provocação interessante, nesse sentido, feita pela autora, qual podemos utilizar, igualmente, nos estudos de pertencimento e ensino sobre culturas indígenas.

Apesar do desconstrucionismo pós- $1960^{4}$, o indivíduo racional, humanista, é posto em xeque, mas a relação com o descentramento 
permanece "autoconsciente" (STRATHERN, 1999; VIVEIROS DE CASTRO, 2004; 2012). Os corpos além-humanos para os indígenas, próteses e transplantes (continuum homem-máquina) para o Ocidente, questionam não apenas a condição de indivíduo e corpo, como também o próprio entendimento de humano e pertença histórica (HARAWAY, 1991; 2011). Recorremos aos indígenas para entender corpos que transformam-se em corpos animais e órgãos que se transmutam em objetos ${ }^{5}$ (OVERING, 1985; VILAÇA, 2013; 2014).

É irônico pensar as representaçóes e a ocidentalização do ensino, portanto, porque falamos em contradiçóes que não se resolvem (STRATHERN, 2014). A tríade ensino-identidade-representação expressa a tensão em manter coisas incompatíveis, sob a mesma égide "harmônica". O privilégio objetivista em não marcar-se é proeminente branco, masculino, universalista e falocêntrico (DAS, 2015; HARAWAY, 1995; SMITH, 2012), ao mesmo tempo que entender identidade e cultura como única e potenciais formas de representação aniquila outros sistemas e possibilidades de vida (VIVEIROS DE CASTRO, 2004; 2012; KOPENAWA; ALBERT, 2010).

\section{AUSÊNCIA DO “OUTRO”, O INTELECTUAL INDÍGENA}

Eu não passo dever "adiantado", peço que perguntem às famílias quem teve avó, bisavô, tataravó indígena que foram "pegas no laço". Eu tive duas avós pegas no laço e por isso meu traçado indígena na cara [sic]. Nas próprias famílias pelo ato de violência praticado contra mulheres nativas, não precisamos ir muito longe, temos descendentes indígenas e material para trabalhar. Depois eu introduzo a leitura e vou explorando os conhecimentos. [...] Já tive coisas riquíssimas vindo da origem das famílias. Também é muito complicado trazer essa linguagem tão etérea. As crianças e até eu, no início, não entendia muito bem, mundos com duas ou três mães, outras formas de conhecimento que misturam, cruzam, espírito com o conhecimento [sic]. Estamos acostumados a ensinar como folclore, mas náo é folclore, é um conhecimento que nossa linguagem não entende, vai além do limite. Por isso busco o intercultural (PROFESSORA DA REDE ESTADUAL DE ENSINO. Entrevista concedida à autora em outubro de 2017). 
Desse testemunho ${ }^{6}$ decorre uma série de narrativas, inclusive o fato dos Estados-naçôes atribuírem "um tipo particular de subjetividade às mulheres, enquanto vítimas de estupro e rapto, quando suas posiçóes de sujeito e subjetividade, embora atoladas nessas construçóes, não foram completamente determinadas por elas" (DAS, 2011, p. 11). Vamos seguir com foco apenas na "interculturalidade", mas destacamos a observação.

De acordo com a CEPAL/UNESCO (2018), o termo evidencia um choque teórico no contexto latino-americano. Abrange estudos que expressam teorias essenciais e autênticas, a leituras híbridas e que se transportam. O conceito ampliou as reformas curriculares, assim como Lei $n^{\circ} 11.645 / 08$ e o Parecer $n^{\circ} 14 / 15$, exaltando a obrigatoriedade do ensino indígena. As políticas têm conseguido, nesse contexto, a problematizaçấo do ensino e das identidades estereotipadas. Este é um ponto positivo para o currículo e para os indígenas, entretanto, em vez de olhar para o contraste apenas no nível legislativo, quero levar o argumento em outra direção.

Um estudo produzido por pesquisadores ameríndios observou que grande parte dos materiais didáticos náo inclui a presença dos autores indígenas e suas literaturas, apesar do esforço das obras antropológicas recentes (BANIWA, 2011; BENITES, 2012). Argumento que, embora a busca pela interculturalidade e a procura por representaçôes nativas "autênticas", tanto quanto "originais", ainda restringimos o conhecimento indígena a uma linguagem desencantada e normativa (BANIWA, 2011; TAIAIAKE, 2009; CHAKRABARTY, 1992; 2012). As colocaçóes de Bartomeu Melià, um dos primeiros autores a difundir o conceito na América Latina, são esclarecedoras nesse sentido (BASTOS LOPES, 2016).

Interculturalidade é um termo conceitualmente bom, um conceito válido, entretanto, muito enganoso. Por que enganoso? Porque falamos de interculturalidade e de fato nós oferecemos ao negro, ao índio, ao Outro, oportunidades para que estes possam cursar a nossa cultura, isto é, levamos o que nós consideramos médio ou inferior para estes. Oferecemos fórmulas para assimilar o outro ao nosso modo de ser e isso chamamos de interculturalidade; não se trata de um verdadeiro ato de escuta do outro; apenas possibilitamos um diálogo conosco, mas, não estamos prontos 
para ouvir; interculturalidade seria nós dialogarmos também com eles, precisaríamos escutar o outro e tal fato não acontece. Interculturalidade não é abrir o caminho para o índio aprender português; interculturalidade seria o Brasil inteiro saber uma língua indígena pelo menos. Se de fato existisse interculturalidade, a nossa própria mentalidade aceitaria outros sistemas de vida e outros costumes. Nesse sentido, o índio é muito mais aberto, mais intercultural, porque facilmente passa a nos entender, mas nós dificilmente o entendemos. Se a discriminaçáo continuar, não teremos dado o menor passo em matéria de interculturalidade (MELIÀ apud BASTOS LOPES, 2016, p. 296).

Entre muitos pontos que abrangem a interculturalidade (aproximação, afastamento, renarração), Melià (BASTOS LOPES, 2016) afirma a qualidade enganosa do conceito, quando apenas famílias e alunos indígenas alfabetizam-se na língua dominante. $\mathrm{O}$ ensino indígena passa a ser confundido exclusivamente com a alfabetização em português ou castelhano.

Em um estudo ainda em vias de conclusão ${ }^{7}$, ao mapear 600 produtos que analisam a representação ameríndia no material didático na regiáo Sudeste, encontramos apenas $7 \%$ de autoria indígena, concentrada quase exclusivamente nos mesmos pesquisadores, sem grande variação ou internacionalização das autorias. A pesquisa ainda é recente, mas já esboça marcos globais nos materiais didáticos (ESCOBAR, 2014).

Como argumenta Vilaça (2013), acerca da noção dos povos Wari', que aqui aproximo a práticas particularmente da Lei no 11.645: "Não se sai de um ritual com a solução do alívio do conflito de valores, mas com a certeza da existência de outros tipos de seres e com um determinado tipo de relação estabelecido entre eles; em suma, sai-se com um 'novo mundo"” (VILAÇA, 2014, p. 46). O "novo mundo", com seres, objetos, rituais, passa pela relação ao que não é somente contrário ao branco ou "autêntico" nativo, mas estabelece como as culturas e linguagens são distintas umas das outras (DESCOLA, 2010; VIVEIROS DE CASTRO, 2012; OVERING, 1985).

A literatura indígena e as escolas desfiam a relação entre racionalidade e conhecimento/conhecimento e xamanismo (KOPENAWA; 
ALBERT, 2010; BENITES, 2012; SILVA, 2013). É curioso, portanto, como objetificamos o ensino em representaçóes racionais, mesmo nos valendo da interculturalidade como norma (BASTOS LOPES, 2016; MELIÁ, 2010).

\section{SALAS DE AULA, LEITURA E A LEI N 11.645}

Nas primeiras e sucessivas imersóes em salas de aula, observei a capacidade crível dos alunos para interessarem-se primeiro pelos objetos (de distintas culturas, variaçôes e formas) e depois pelas falas ou pessoas. $\mathrm{O}$ costume em perguntar sobre peças, anteriormente produzidas com sementes e atualmente por materiais plásticos, gera re-narração e afastamento em relação aos indígenas. A fala da segunda professora sugere exatamente esse universo de deuses, mundos físicos e cosmológicos encarnados.

Como bem aponta Edson Krenak, a literatura indígena expressa um desafio para os estudos literários, linguísticos e textuais dentro da academia.

Os conceitos e regras estéticas, performáticas aplicadas ao texto canônico da literatura brasileira, não são facilmente aplicados à literatura indígena. Isso porque o sistema literário é outro, sua razáo de existir (história) é outra, embora use o sistema da indústria cultural (autor, livro e leitor) como meio para difundir-se (ANDRADE, 2019, grifos nossos).

Krenak, Daniel Munduruku e Eliane Potiguara ${ }^{8}$ afirmam como a ocidentalização encara sistemas de linguagem nos quais deuses, espíritos e pessoas participam ativamente do pensamento (KOPENAWA; ALBERT, 2010; VILAÇA, 2013; VIVEIROS DE CASTRO, 2012). Esses autores têm percorrido escolas e congressos ressaltando como a literatura indígena apresenta diferentes sistemas de inteligilidades. Abaixo, a experiência do professor José Guajajara, que percorre escolas difratando a Lei no 11.645.

Produzo esse trabalho intercultural, antes de ficar famosa a palavra. Comecei em 1995-1996 visitando junto com outros parentes e depois fui sozinho às escolas e centros universitários. Acho importante os brancos entenderem. Faço isso há muitos anos, bem 
antes da Lei no 11.645/08 [sic]. O que eles estudam são os Pataxó, Guarani, Guajajara, Xavante, são universos muito diferentes e que os professores, por não terem nossa vivência, não entender dos nossos espíritos, manejo na política, não vão conseguir explicar sozinhos. Nossas culturas são menos de livros e mais de espírito, entende [sic]. As rodas de conversa que tenho com alunos, professores, ainda que não tenha fogueira e os mais velhos [refere-se à ancestralidade], é o mais próximo que consigo levar do meu conhecimento.

\section{AS AULAS NO INSTITUTO FERNANDO RODRIGUES DA SILVEIRA: CAP-UERJ}

Os estudos de Guajajara oferecem os elementos-chave para a interculturalidade, associado a outros contextos escolares que resumo como se segue.

O trabalho com projetos, destacadamente o Projeto Pensando Culturas Ameríndias ${ }^{9}$, agrupa vários anos de escolaridades e núcleos específicos. Os participantes são alunos, professores, bolsistas, não havendo restrição por faixa etária ou outro critério seletivo. Como comum às aulas, não existe obrigatoriamente o direcionamento ou a adaptação do material didático a determinado currículo e ano escolar. Os participantes leem artigos, tanto quanto periódicos acadêmicos, acervos de teatro e museu. A não didatização de um material objetificado à determinada idade influencia o instituto assim como as particularidades em relação ao uso e desuso do material estabelecido.

Os participantes estabelecem-se em grupos, em rodas de conversas, e não em fileiras (ALMEIDA, 2016; OLIVEIRA, 2014). Isso cria um ambiente que provoca diferentes contextos, expressóes e estranhamentos. Além do acervo bibliográfico, as turmas acessam objetos, arte plumária e museal indígena. Trabalham com a concepção e associação da leitura com a pesquisa bibliográfica. Muitos analisam instrumentos musicais, performam estudos a partir das cestarias e dos grafismos.

A participação tem me permitido acompanhar o estranhamento e a sedução nos diferentes grupos, tanto quanto temas específicos. 
As aulas concebem não apenas o recebimento da informação, mas o estudo do material e dos artefatos recebidos, analisados e catalogados. Mais do que reafirmar o precário e o autêntico em relação ao ensino com culturas indígenas, observa-se como os universos e sistemas são complexos, apesar de apresentados por meio de uma linguagem racionalista.

Algumas turmas acompanhei por dois a três anos ininterruptos. Os conhecimentos que pareciam particularmente estranhos para alguns, (desenhavam indígenas comendo brancos ${ }^{10}$, estuprando mulheres ou invadindo terras ${ }^{11}$ ), ao final, expunham narrativas menos estereotípicas, ainda que mantivessem estranhamentos. Muitos manuseiam objetos de modo idêntico ou analogamente semelhante às culturas que pesquisam. Três alunos, em específico, tocam o instrumento de chamamento de pássaros (Mimby) de modo similar ou quase idêntico ao Guarani ${ }^{12}$. O que observei com curiosidade ao longo dos anos.

O tempo, portanto, parece estabelecer-se como agência (DAS, 2011; 2015); atravessa as re-narraçóes e os sistemas de representação. Como argumenta Venna Das (2011), o tempo adquire um valor particular e náo pode ser encarado como elemento exclusivamente abjeto ou afastado da subjetividade. O passado é indeterminado e o "trabalho do tempo" manifesta formas de re-narração e diferença (DAS, 2011; 2015). Não estou afirmando, a essa altura, que os indígenas devam ser buscados como chaves de acesso para "mundos não vistos" ou "civilizaçóes prontas". O mundo pronto é universalizante para os indígenas assim como para qualquer cultura assimétrica por tradição (APPADURAI, 2013; BHABHA, 1994; CHAKRABARTY, 2011; 2012). Entretanto, é curioso como a leitura dos autores indígenas e as histórias provocam conflitos nas narrativas.

\section{VERSÕES E VARIAÇÕES PARA O MATERIAL DIDÁTICO}

Por toda a América Latina existem arquivos de lugares e objetos, assim como nomes de ruas e bairros escritos em línguas ameríndias (FREIRE, 2014). Sites como o Pró-Índio Uerj (www.proindiouerj.blogspot.com.br), produzido pelo professor José Bessa Freire, o Escritores Indígenas (escritoresindigenas.blogspot.com.br) e o Portal das Memórias da África e do Oriente (memoria-africa.ua.pt) são comumente acessados pelas escolas na procura dessas informaçóes. 
Os materiais, em 2013, eram desconhecidos ou raramente utilizados pelos professores, o que apresenta um indicador relevante. O fluxo do uso dos livros didáticos associa uma utilização menos normativa, exposta a possibilidades do inesperado durante as aulas (MILLER, 2014). Os exercícios costumam associar o "passado" com o contemporâneo, comparando iconografias indígenas do período jesuítico colonial a imagens recentes das populaçóes (BASTOS LOPES, 2017). Esse reconhecimento da localização antiga, contrastado com as localizaçóes modernas, analisa uma variabilidade de aspectos, como convergências, migração de culturas, assim como as alteraçóes nos significados e inversóes culturais.

Também nas escolas do município as comparações são comuns (BASTOS LOPES, 2013; 2017 FREIRE, 2014). Em muitos casos a noção de tempo-espaço é contrastada com a temporalidade das cosmologias. Um aspecto recorrente são as construçóes de acervos com artefatos e fotografias que existem nas três escolas.

Entendo que o desafio foi o de descolonizar "como estudamos culturas" à margem dos universalismos e marcos globais (ESCOBAR, 2014), contudo é como se não escapássemos ao comparativismo para representar os indígenas. Como afirma Viveiros de Castro (2004; 2012), a "nossa cultura" é também uma etno, outra "alguma coisa", embora não a denominemos com os prefixos etno, inter, alter etc. Estabelecer outras formas de leitura e comunicação com os textos ameríndios é um desafio ao longo da "agência do tempo" colocado às escolas (DAS, 2011; 2015).

\section{CONSIDERAÇÕES FINAIS}

A Lei no 11.645/08 é marcada, portanto, por uma multiplicidade de trabalhos, e não pela falta deles (BASTOS LOPES, 2013).

O contato com mundos pouco humanistas diversifica outros corpos e sistemas de racionalização e diferença (VILAÇA, 2013, 2014; VIVEIROS DE CASTRO, 2012). O intuito do artigo não foi descrever projetos de sucesso, contrastando com os que "náo funcionam", evidenciando, assim, quais seriam os materiais corretos ou as escolas qualificadas. $\mathrm{O}$ que se apresenta é a importância do estranhamento a partir das literaturas indígenas, mesmo com a linguagem desencantada e ocidental presente em nossa cultura predominantemente racionalista. 
Argumento que aos poucos estamos experimentando outras "didáticas possíveis", expostas às possibilidades de pensamento e linguagens complexas. A Lei $n^{\circ}$ 11.645/08 abre possibilidades na mesma proporção que é contraditória, ao marcar o diferente em uma racionalização ocidental para ser incluído, porém não se faz menos importante ou emergente porque é contraditória.

Os discursos a favor da interculturalidade ou diferença não atingirão seus objetos "meteóricos", "didáticos", se continuarem a expor culturas indígenas em uma linguagem adaptada ou traduzida por autores majoritariamente brancos, coloniais e desencantados (CHAKRABARTY, 2012). Argumento que outros mundos possíveis são conhecidos na aproximação com outros sistemas e possibilidades de vida, assim como suas literaturas.

\section{REFERÊNCIAS}

ALMEIDA, M.A.O.A. Ação afirmativa de corte racial na educação básica em uma escola de excelência: a experiência do Instituto de Aplicação Fernando Rodrigues da Silveira - CAp-UERJ. 281f. Tese (Doutorado em Educação) - Pontifícia Universidade Católica do Rio de Janeiro, Rio de Janeiro, 2016.

ANDRADE, E. D. O indígena como usuário da lei: um estudo etnográfico de como o movimento da literatura indígena entende e usa a Lei $\mathrm{n}^{\circ} 11.645 / 2008$. Caderno Cedes, Campinas, v. 39, n. 109, p. 321-356, set.-dez. 2019. http://doi. org/10.1590/CC0101-32622019217105

APPADURAI, A. The Future as a cultural fact: essays on the global condition. London: Verso Books, 2013.

The social life of things: commodities in cultural perspective. Nova York: Cambridge University Press, 1986.

BANIWA, G.J. dos S.L. Educação para manejo e domesticação do mundo: entre a escola ideal e a escola real: os dilemas da educação escolar indígena no Alto Rio Negro. 370f. Tese (Doutorado em Educação) - Universidade de Brasília, Brasília, 2011.

BARRIGA, A.D. Impacto de las políticas de evaluación y calidad en los proyectos curriculares. In: DE ALBA, A.; LOPES, A. C. (coords.). Diálogos curriculares entre México y Brasil. México: UNAM/IISUE, 2015. p. 139-164.

BASTOS LOPES, D. E todo dia era dia de índio: a representaçáo dos povos indígenas nos currículos escolares do Rio de Janeiro. Revista Poiésis, v. 7, n. 11, p. 96-113, 2013. http://dx.doi.org/10.19177/prppge.v7e11201396-112 
. Entre a terra e o céu guarani: uma conversa com Bartomeu Melià. Espaço Ameríndio, Porto Alegre, v. 10, n. 2, p. 289-298, 2016. https://doi. org/10.22456/1982-6524.69950

. Pensando culturas ameríndias: usos e desusos do material didático em um instituto de aplicação. In: CASTANHEIRA, M.; PINTO, F.; BASTOS, L.; ALVARENGA, R. (orgs.). Maçã com Canela: produtos educacionais e outros textos. Rio de Janeiro: Publit, 2017. p. 31-38. (Coleçáo Chás para a Filosofia).

BRASIL. Diretrizes para a Política Nacional de Educação Escolar Indígena. Ministério da Educação, 1994. Brasília: MEC. http://portal.mec.gov.br/cne/.

Referencial Curricular Nacional para as Escolas Indígenas. Ministério da Educação. Brasília: MEC, 1998. http://portal.mec.gov.br/cne/.

Parâmetros em Ação Educação Escolar Indígena. Ministério da Educação. Brasília: MEC, 2002. http://portal.mec.gov.br/cnel.

. Lei $\mathrm{n}^{\circ} 11.645$. Altera a Lei $\mathrm{n}^{\circ}$ 9.394, de 20 de dezembro de 1996, modificada pela Lei $\mathrm{n}^{\circ} 10.639$, de 9 de janeiro de 2003, que estabelece as diretrizes e bases da educação nacional, para incluir no currículo oficial da rede de ensino a obrigatoriedade da temática "História e Cultura Afro-Brasileira e Indígena". Diário Oficial da República Federativa do Brasil. Brasília: Senado Federal, 2008.

BENITES, T. A escola na ótica dos Avá Kaiowá: impactos e interpretaçóes indígenas. Rio de Janeiro: Contracapa, 2012.

BHABHA, H.K. The location of culture. London/New York: Routledge, 1994.

CESARINO, L. Antropologia multissituada e a questão da escala: reflexốes com base no estudo da cooperação sul-sul brasileira. Horizontes Antropológicos, Porto Alegre, v. 20, n. 41, p. 19-50, 2014. http://dx.doi.org/10.1590/S010471832014000100002

CHAKRABARTY, D. From civilization to globalization: the 'West' as a shifting signifier in Indian modernity'. Journal Inter-Asia Cultural Studies, v. 13, n. 1, p. 138-152, 2012. https://doi.org/10.1080/14649373.2012.636877

. Postcoloniality and the Artifice of History: Who Speaks for "Indian" Pasts? Representations, Nova York, n. 37, p. 1-26, 1992.

. The muddle of modernity. The American Historical Review, Oxford, v. 116, n. 3, p. 663-675, 2011. https://doi.org/10.1086/ahr.116.3.663

COMISIÓN ECONÓMICA PARA AMÉRICA LATINA Y EL CARIBE (CEPAL)/ORGANIZAÇÃO DAS NAÇÓES UNIDAS PARA A EDUCAÇÃO, A 
CIÊNCIA E A CULTURA (UNESCO). Boletín de la infancia y adolescencia sobre el avance de los objetivos del desarrollo del milenio, Santiago. Desafios, n. 21, p. 1-32, 2018. https:/www.cepal.org/es/publicaciones/tipo/challenges-newsletter/21

CORTÉS, A.R.; APODACA, E.G. El carácter interactoral en la Educación Superior con enfoque intercultural en México. Revista Liminar, México, v. 14, n. 1, p. 73-91, 2016.

DAS, V. Affliction: health, disease, poverty. New York: Fordham University Press, 2015.

. O ato de testemunhar: violência, gênero e subjetividade. Cadernos Pagu, São Paulo, v. 37, p. 9-41, 2011. http://dx.doi.org/10.1590/S0104$\underline{83332011000200002}$

DERRIDA, J. O animal que logo sou. São Paulo: Editora da Unesp, 2011.

DESCOLA, P. Diversité des natures, diversité des cultures. Paris: Bayard Culture, 2010.

DIAS, R.E. Organização curricular: um campo de antagonismos. In: LOPES, A.; DE ALBA, A. (orgs.). Diálogos curriculares entre Brasil e México. Rio de Janeiro: EdUERJ, 2014. p. 277-293.

ESCOBAR, A. America Latina en una encrucijada: ¿̇modernizaciones alternativas, posliberalismo o posdesarrolo? In: QUINTERO, P. (orgs.). Crisis Civilizatoria, Desarrollo y Buen Vivir. Buenos Aires: Del Signo, 2014. p. 59-106.

FERGUSON, J. Global Shadows: Africa in the neoliberal global world order. Durham: Duke University Press, 2006.

FREIRE, J.R.B. A demarcação das línguas indígenas no Brasil. In: CARNEIRO DA CUNHA, M.; CESARINO, P. de N. (orgs.). Politicas culturais e povos indígenas. São Paulo: Cultura Acadêmica, 2014. p. 363-389.

GELLNER, E. Anthropology and Politics: revolutions in the sacred grove. Oxford: Wiley-Blackwell Publisher, 1995.

HARAWAY, D.J. A partilha do sofrimento: relaçóes instrumentais entre animais de laboratório e sua gente. Horizontes Antropológicos, Porto Alegre, v. 17, n. 35, p. 27-64, 2011. http://dx.doi.org/10.1590/S0104-71832011000100002

- Saberes localizados: a questáo da ciência para o feminismo e o privilégio da perspectiva parcial. Cadernos Pagu, Sáo Paulo, n. 5, p. 7-41, 1995. https:// periodicos.sbu.unicamp.br/ojs/index.php/cadpagu/article/view/1773 
. Simians, Cyborgs and Women: the reinvention of nature. New York: Routledge, 1991.

KOPENAWA, D.; ALBERT, B. La chute du ciel paroles d'um chaman Yanomami. Paris: Plon, 2010.

LATOUR, B. Jamais Fomos Modernos: ensaio de antropologia simétrica. São Paulo: 34, 2013.

MACEDO, E. Equity and difference in centralized policy. Journal of Curriculum Studies, Philadelphia, v. 45, n. 1, p. 28-38, 2013. https://doi.org/10.1080/002 $\underline{20272.2012 .754947}$

. Mas a escola não tem que ensinar? Conhecimento, reconhecimento e alteridade na teoria do currículo. Currículo Sem Fronteiras, Rio de Janeiro, v. 17, n. 3, p. 539-554, 2017.

MARCUS, G. Ethnography in/of the world system: the emergence of multisited ethnography. Annual Review of Anthropology, v. 24, n. 1, p. 95-117, 1995. https://doi.org/10.1146/annurev.an.24.100195.000523

MELIÀ, B. Passado, presente y futuro de la lengua guaraní. Asunción: CEADUC/ ISEHF, 2010.

MILLER, J. Teorização do currículo como antídoto contra/na cultura da testagem. Revista e-Curriculum, São Paulo, v. 12, n. 3, p. 2043-2063, 2014.

OLIVEIRA, C.S. E você não quer, faça matrícula no pagou-passou da esquina. Concepçôes de currículo e avaliação: diálogos sobre um colégio de excelência. $110 \mathrm{f}$. Dissertação (Mestrado em Educação) - Universidade do Estado do Rio de Janeiro, Rio de Janeiro, 2014.

OLIVEIRA, T.R.M.; BASTOS LOPES, D. On the limits of the non/human in the field of curriculum. Curriculum Inquiry, v. 26, n. 1, p. 110-125, 2016. https://doi.org/10.1080/03626784.2015.1113512

ONG, A.; COLLIER, S. J. Global assemblages: technology, politics and ethics as anthropological problems. Malden: Wiley - Blackwell, 2005.

OVERING, J. There is no end of evil: the guilty innocents and their fallible god. In: PARKIN, D. (Ed.). The Anthropology of Evil. Oxford: Basil Blackwell, 1985. p. 244-278

ROCKWELL, E. Conversaciones en torno a la educación con pueblos indígenas/ migrantes. In: NOVARO, G.; PADAWER, A.; HECHT, A. Educación, Pueblos 
Indigenas y Migrantes: reflexiones desde México, Brasil, Bolivia, Argentina y España. Buenos Aires: Biblos, 2015. p. 11-39.

SAID, E. W. Orientalismo: o Oriente como invenção do Ocidente. São Paulo: Companhia das Letras, 2007.

SILVA, A. Mboapy nhanderuvixa tenondé guải oexaraùu vaee kuery Tekoa Sapukai py guá: kaxo yma guare, nheée ngatu, nhembojera [Três sonhadores do Tekoa Sapukai: história, oralidade, saberes]. 30f. Trabalho de Conclusão de Curso (Licenciatura em Educação do Campo) - Universidade Federal Rural do Rio de Janeiro, Seropédica, 2013.

SMITH, L.T. Decolonizing methodologies: research and indigenous peoples. London: Zed Books, 2012.

STRATHERN, M. O efeito etnográfico. São Paulo: Cosac Naify, 2014.

. Property Substance and Effect: anthropological essays on persons and things. London: Athlone Press, 1999.

TAIAIAKE, A. Wasáse: indigenous pathways of action and freedom. Toronto: University Toronto Press, 2009.

VILAÇA, A.M.N. Two or three things that I know about talking to the invisible. HAU: Journal of Ethnographic Theory, Chicago, v. 3, n. 3 p. 359-363, 2013. https://doi.org/10.14318/hau3.3.016

. De ritos e mundos. Debates do NER, Porto Alegre, v. 2, n. 26, p. 45-48, 2014. https://doi.org/10.22456/1982-8136.52035

VIVEIROS DE CASTRO, E. Cosmological perspectivism in Amazonia and elsewhere. Hau: Journal of Ethnographic Theory, Chicago, v. 1, p. 45-168, 2012. (Masterclass Series.)

. Perspectival anthropology and the method of controlled equivocation. Tipití, Oxford, v. 2, n. 1, p. 3-22, 2004. http://digitalcommons.trinity.edu/tipiti/vol2/iss1/1

YAPU, M. La socialización indígena y escolarización de niños menores de siete años. In: NOVARO, G.; PADAWER, A.; HECHT, A. (orgs.). Educación, Pueblos Indigenas y Migrantes: reflexiones desde México, Brasil, Bolivia, Argentina y España. Buenos Aires: Biblos, 2015. p. 255-282.

\section{NOTAS}

1. Ao elencar um método, o que se apresenta éo etnográfico. São alguns exemplos: etnografias multissituadas (MARCUS, 1995), redes sociotécnicas (LATOUR, 2013), processos de 
espacialização (FERGUSON, 2006) ou os métodos como paisagens (APPADURAI, 1986), composiçóes (ONG; COLLIER, 2005) e os globe-hopping, culturas em espaços variados (FERGUSON, 2006). Vemos a discussão em Cesarino (2014, p. 20). Aproximo-me, neste artigo, das escalas e relaçóes virtuais estabelecidas por M. Strathern (1999; 2014), qual a metodologia é pensada com o falante enfatizando o modo como os próprios interlocutores, virtualmente localizados, produzem conhecimento em articulação com quem realiza a pesquisa (STRATHERN, 1999; 2014).

2. O Programa Nacional do Livro Didático (PNLD) é um programa do Ministério da Educação e Cultura (MEC), qual as escolas públicas devem selecionar livros avaliados por uma equipe interinstitucional. É incumbência dos professores e da equipe pedagógica analisar as resenhas contidas no PNLD para elencar os livros utilizados durante o triênio. Os professores selecionam o material pela internet no portal do Fundo Nacional de Desenvolvimento da Educação (FNDE). A escola pode apresentar duas opçóes na escolha das obras para cada disciplina, mas baseada apenas na lista indicada, caso náo seja possível a primeira opção, o FNDE envia à comunidade escolar a segunda escolhida. Disponível em: <http://portal.mec.gov.br/pnld/>. Acesso em: 11 set. 2018.

3. Não me estenderei nas questóes sobre os aspectos humanistas e universais propostos pelos modelos do Currículo Nacional para a Educação Indígena (BRASIL, 1998; 2002; 1994, entretanto, destaco trabalhos anteriores onde analiso o tema (BASTOS LOPES, 2016; 2017).

4. Falo aqui do movimento teórico ocorrido no período pós-guerra, vigente na Guerra Fria, particularmente influenciado pelos movimentos pós-modernos, algumas ramificaçóes denominadas pós-estruturais, os últimos com a influência dos autores Foucault, Deleuze e destacadamente Jacques Derrida.

5. Sobre a noção de pessoa, corporalidade e a transformação de homens em animais, animais em homens, sugiro ver: Descola (2010), Vilaça (2013; 2014), Viveiros de Castro (2012) e a obra de antropólogos ameríndios como Kopenawa e Albert (2010).

6. Sobre as possibilidades da palavra-testemunho, concordo com as especificaçóes da etnógrafa palestina Venna Das (2011, p. 11-12), ao afirmar que: "Alguns antropólogos se perguntam se a noção do testemunho pode ser posta como lugar analítico a partir do qual escrever, porque argumentam que o forte substrato cristão desse conceito o torna uma categoria inadequada, quando não suspeita, para o trabalho antropológico. Considero essa posiçáo excessivamente restritiva, como se outras culturas (p. ex., o Islã e o Hinduísmo) não tivessem noções de testemunho. [...] De qualquer maneira um conceito náo se torna ilegítimo porque suas origens possam estar situadas num discurso adjacente, seja religião ou ciência, a menos que se possa mostrar a maneira específica em que ele afeta a descrição. De minha parte, as noçóes de testemunho são aqui apresentadas não para atestar a fé diante do corpo mutilado, mas a criatividade da vida. Isso não quer dizer que outras noçóes de testemunho como no caso dos campos nazistas náo sejam extremamente poderosas. Porém, nem todas as formas de violência e lembrança podem ser recontadas através desse modelo". 
7. O projeto de pesquisa que coordeno "Entre a terra e o céu ameríndio: currículo, cultura e diferença", financiado pela Fundação de Amparo à Pesquisa do Estado do Rio de Janeiro (FAPERJ), tem o objetivo de analisar a representação indígena nos materiais didáticos, assim como teses e dissertaçôes do quadriênio 2014-2018. A pesquisa foi iniciada em 2017 e analisou, até o momento, 600 produtos nos bancos de dados da Coordenaçáo de Aperfeiçoamento de Pessoal de Nível Superior (CAPES) e Conselho Nacional de Desenvolvimento Científico e Tecnológico (CNPq).

8. Daniel Munduruku, Eliane Potiguara e Edson Krenak são escritores influentes no movimento literário indígena. Daniel Munduruku, destacadamente, atuou como presidente do Instituto Indígena Brasileiro para Propriedade Intelectual (INBRAPI).

9. O Projeto Pensando Culturas Ameríndias ocorreu entre os anos 2016 e 2017 no Instituto de Aplicação Fernando Rodrigues da Silveira (CAp-UERJ).

10. O endocanibalismo foi uma prática comum entre os Wari de Rondônia (VILAÇA, 2013; 2014) e as socialidades amazônicas; atualmente é revisitada em novos contextos, como o costume de beber o corpo morto (celebraçôes em que se ingere bebidas alcoólicas em ritos funerários), e em algumas culturas já foi totalmente extinto (VILAÇA, 2013; 2014). O contexto do endocanibalismo e suas variaçôes foram expostos durante as aulas; as primeiras narrativas produzidas pelos alunos eram de que todos os indígenas, por desconhecerem Deus, eram canibais e violentadores de mulheres.

11. Ao que me refiro como violência considera aulas cuja menção aos indígenas foi adjetivada como bêbados, alcoólatras, usurpadores de terras, atrasados, devoradores de mulheres. Em um episódio particular, ao perguntar o que a criança entendia por usurpador, ela informou desconhecer o significado exato da palavra, mas afirmava que deveria ser uma qualidade ruim, já que tudo o que o "índio faz é atrasado ou ruim [sic] para o país".

12. Os Mbyá, conhecidos também como Guarani-Mbyá, são socialidades indígenas presentes na regiáo Sudeste do Brasil, habitam a Argentina, Bolívia, Uruguai e Paraguai. No Estado do Rio de Janeiro, especificamente, residem na cidade de Paraty desde 1950. Foram contactados por volta dos anos 1970, devido à abertura da Rodovia Rio-Santos. Atualmente existem sete Terras Indígenas (TIs) no estado e três territórios homologados pela Fundação Nacional do Índio (FUNAI) (BASTOS LOPES, 2017).

Recebido em 6 de fevereiro de 2019.

Aprovado em 9 setembro de 2019.

(C) 2019 Centro de Estudos Educação e Sociedade - CEDES Este é um artigo de acesso aberto distribuído nos termos de licença Creative Commons. 